\title{
Thermal design and characterization of a modular integrated liquid cooled 1200V-35A SiC MOSFET bi-directional switch
}

\author{
P. Cova ${ }^{\text {a, }}$, A.M. Aliyu ${ }^{\text {b }}$, A. Castellazzi ${ }^{\text {b }}$ \\ D. Chiozzi ${ }^{\mathrm{a}}$, N. Delmonte ${ }^{\mathrm{a}}$, P. Lasserre ${ }^{\mathrm{c}}$, N. Pignoloni ${ }^{\mathrm{a}}$ \\ ${ }^{a}$ Department of Engineering and Architecture, University of Parma, Italy \\ ${ }^{b}$ PEMC Group, University of Nottingham, Nottingham, UK \\ ${ }^{c}$ PRIMES Association, Tarbes, France
}

\begin{abstract}
The aim of this work is the thermal design of a modular direct liquid cooled package for 1200V-35A SiC power MOSFETs, in order to take full advantage of the high power density and high frequency performance of these devices, in the development of a modular integrated solution for power converters. An accurate electro-thermal fluid dynamic model is set up and validated by thermal characterization on a prototype; numerical models have been used to study the internal temperature distribution and to propose further optimization.
\end{abstract}

\section{Introduction}

The power electronics community demands for increasing frequencies and power density and new semiconductor technologies, based on $\mathrm{GaN}$ or $\mathrm{SiC}$ power devices, depending on the applications, are gaining market. The transistors are expected to soon reach suitable reliability for deployment in applications such as automotive, traction and aerospace, but the bottleneck is now represented by the packaging, which has to ensure low parasitics, good cooling, compactness, maintainability, modularity and competitive cost. Innovative solutions can be found in literature for specific issues as the cooling integration to the module [1]-[5] or highly integrated systems to reduce as much as possible the stray inductances [6], sometime with gate-drivers, power stage, and DC-link in the same package as in [7].

A new integrated liquid cooled bi-directional power switch for matrix converters was developed and recently presented in [8], based on $1200 \mathrm{~V}-35 \mathrm{~A} \mathrm{SiC}$ power MOSFETs. The aim of the present work is the thermal design optimization of the module presented in [8], in order to better exploit the high power density and high frequency performance of these devices. In particular, since the target was the improvement of the direct liquid cooled modular bi-directional switch, an accurate thermal fluid dynamic model was made and validated by thermal characterization on an early prototype. Then, the numerical model has been used to study the internal temperature distribution, and to propose improvements for the next release.

\section{The bi-directional SiC power switch}

The single module is composed by two transistors connected with the source in common (Fig. 1), and the internal layout, as described in [8] and shown in Fig. 2, was designed to obtain low parasitic inductances and good thermal performance. The devices used in this study are $1200 \mathrm{~V}-80 \mathrm{~m} \Omega$ MOSFETs, with dimensions of $3.1 \times 3.6 \mathrm{~mm}^{2}$ and about $200 \mu \mathrm{m}$ thick. For a description of the electrical performance, see [8].

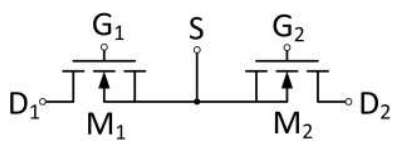

Fig. 1. Electrical diagram of a bi-directional switch.

This first solution, designed specifically for a bidirectional switch, integrates two MOSFETs chips mounted with the drain terminal onto two separate

Corresponding author: Paolo Cova paolo.cova@unipr.it +390521905818 
identical Direct Bonded Copper (DBC) substrates (Fig. 2a); these two substrates are stacked as shown in Fig. $2 \mathrm{c}$, by means of soldered copper $(\mathrm{Cu})$ bumps; two smaller bumps are used (Fig. 2b) to short the source terminals of the two transistors; an additional DBC substrate is partly sandwiched between the other two substrates to realize the power terminals D1 and D2, whereas bond-wires and external leads are used for the gate-drive interconnections (Fig. 2a). The outer cooling surfaces are extended by fins to improve the heat exchange with the liquid flowing in the coolers (Fig. $2 \mathrm{~d})$. The cooling is made by inserting the module in a sealed Teflon modular package, which is crossed by the coolant (typically a water-glycol mixture). Fig. 3 gives a sketch of three packaged modules connected together to make a converter.
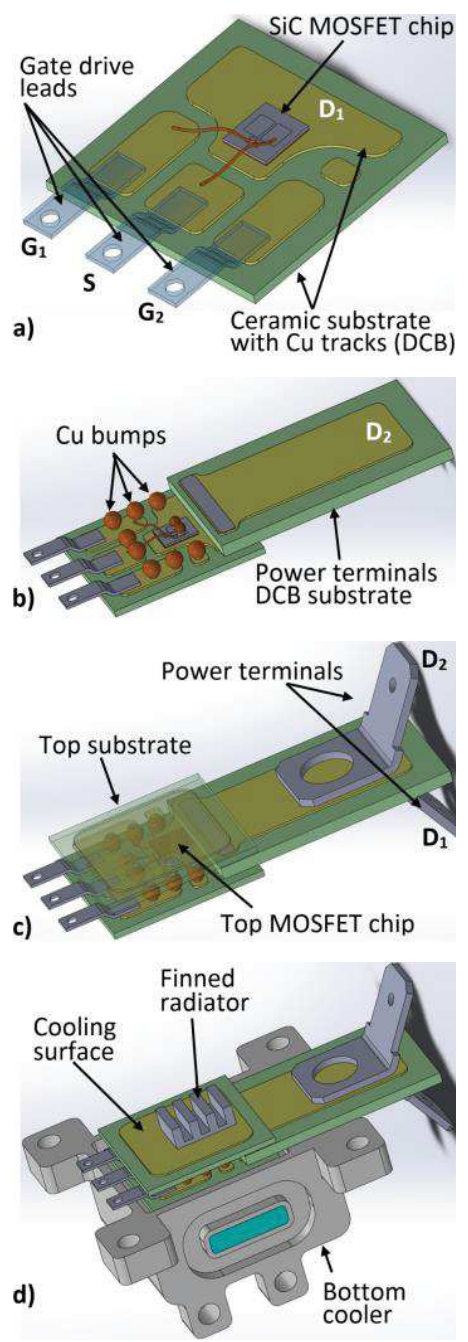

Fig. 2. Layout of the bi-directional power switch contained in a single module.

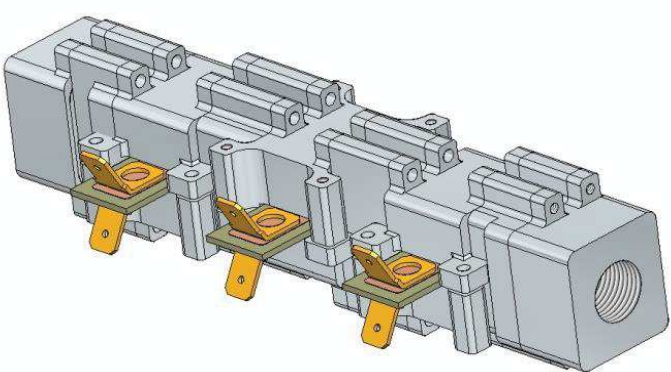

Fig. 3. External view of three packaged modules connected together to make a power converter.

In [8] preliminary thermal simulations were shown, identifying a limit in the operating conditions, which was far from the full exploitation of the power density capability of the transistors. For instance, single bidirectional switch module dissipating $100 \mathrm{~W}$ by each MOSFET, with a $20{ }^{\circ} \mathrm{C}$ water flow of $9 \mathrm{l} / \mathrm{min}$, the maximum die temperature was around $140^{\circ} \mathrm{C}$, which is below of the die limit operating temperature $\left(175^{\circ} \mathrm{C}\right)$, but typically a high value for reliable operation, especially considering solder layers and thermomechanical stresses. Moreover, the earlier numerical model did not account for the power dissipated in the inner connections, which could be not negligible, due to the compact layout.

The effectiveness of the main thermally activated degradation mechanisms of metallic parts (electromigration, chemical reactions, etc.), increases exponentially with temperature and operation above $125{ }^{\circ} \mathrm{C}$ is in general not recommended $[9,10]$. Moreover, solder joints thermo-mechanical stress increases exponentially with the temperature swing, which, in turn, looking at long-period thermal cycles, is related to the maximum temperature. Then, to increase the reliability of the module, it is mandatory to limit its maximum temperature, since it affects both thermal and thermo-mechanical degradation mechanisms.

\section{Prototype thermal characterization}

Since previous thermal fluid dynamic simulations of three modules connected together [8] demonstrated a very small increase of the water temperature from inlet to outlet (less than $1{ }^{\circ} \mathrm{C}$, even with low flow rates), the thermal characterization was performed on a single module.

Fig. 4 shows the schematic diagram of the thermal characterization test bench. The module was cooled by a regulated open water circuit, with a flow meter at the inlet. The temperature of the water at inlet was 
measured by a $\mathrm{k}$ thermocouple, as well as done at the outlet, and a thermometer with resolution of $0.1{ }^{\circ} \mathrm{C}$. The temperature of the external surfaces was measured by an infrared camera (FLIR A325). These surfaces were covered with a thin layer of matt paint in order to obtain the same emissivity by the different parts in the camera view. Fig. 5 shows the single module with a thermocouple placed at the water outlet and the test bench used for the measurements.

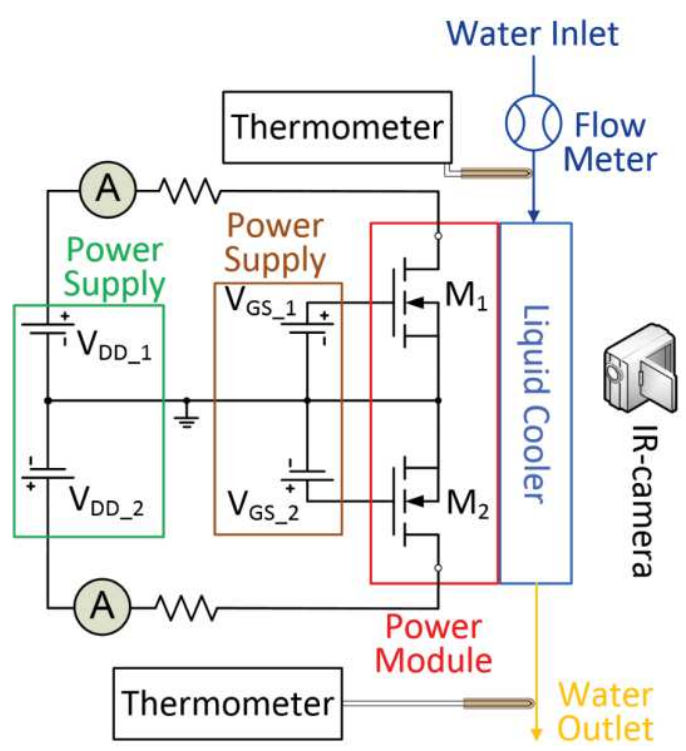

Fig. 4. Schematic diagram of the thermal characterization test bench.
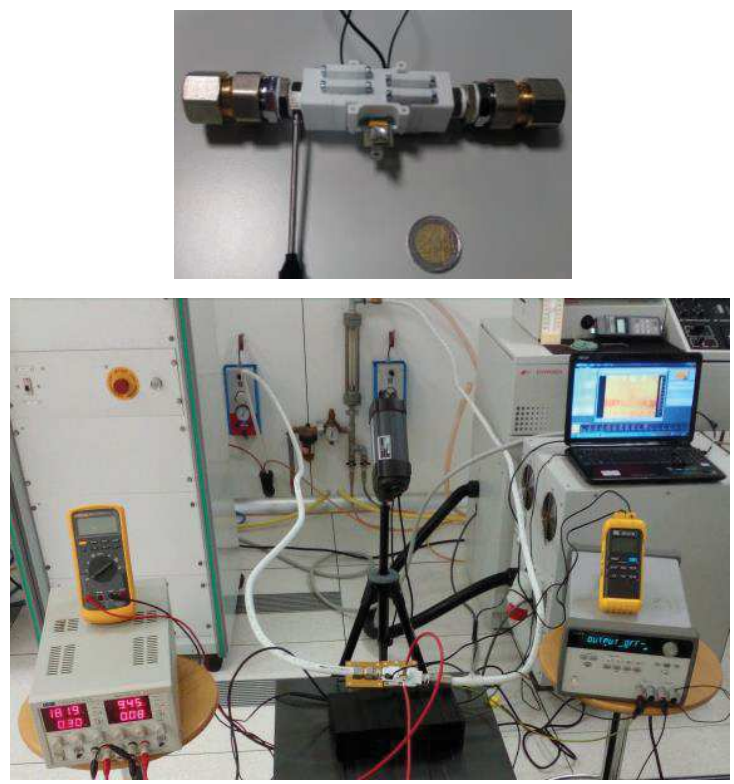

Fig. 5. Single module with a thermocouple at the water outlet (top); thermal characterization test bench (bottom).
To simplify the experimental setup, the MOSFETs were heated simply biasing them in on state and limiting the current by the power supply. This kind of biasing was adopted only for model tuning purposes, and it must be noted that a DC current is then circulated through the source wirebond, although if this does not correspond to the real application. For that reason the current was limited to a safe value of $30 \mathrm{~A}$ (15 A per MOSFET). In these conditions the dissipated power per transistor was $26 \mathrm{~W}$. With a $16^{\circ} \mathrm{C}$ water flow of $2 \mathrm{l} / \mathrm{min}$ the thermal map shown in Fig. 6 was obtained.

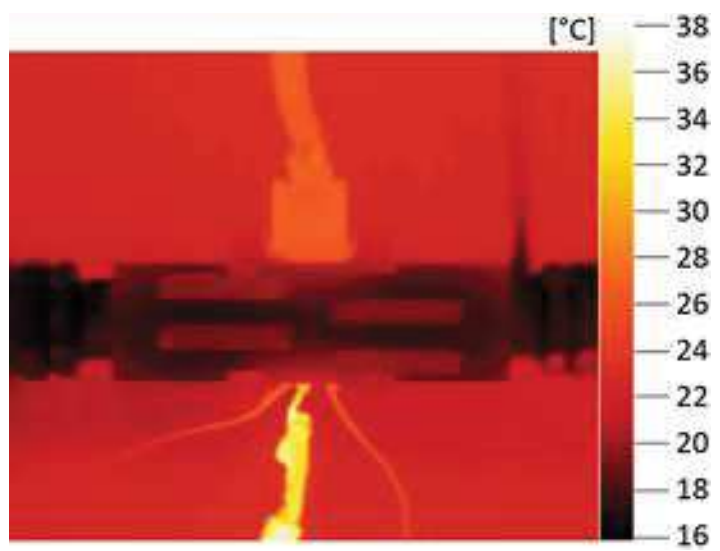

Fig. 6. Measured thermal map of the module dissipating $2 \times 26 \mathrm{~W}$, with a $16^{\circ} \mathrm{C}$ water flow of $2 \mathrm{l} / \mathrm{min}$.

\section{Improved electro-thermal fluid dynamic numerical analysis}

The results of the thermal characterization, looking in particular at the temperature of drain and source external pins, were used to validate the numerical model, hence the cables used to bias the module in DC mode were considered in the simulation. The copper tracks of the module were also taken into account, considering the heat generated by Joule effect within them. The current density flowing in power copper connections was evaluated, solving the Electric Currents equation set in COMSOL Multiphysics [11]. Then, the resulting model can be used to simulate a fully coupled electro-thermal fluid dynamic problem. Fig. 7 illustrates the boundary conditions set in COMSOL Multiphysics to simulate the currents inside the copper connections of drain (blue subdomains) and source (green subdomains). The Electric Insulation condition was set on all the boundary surfaces of green and blue subdomains, except for the surfaces at the terminals, where ground or inward current conditions were set. 


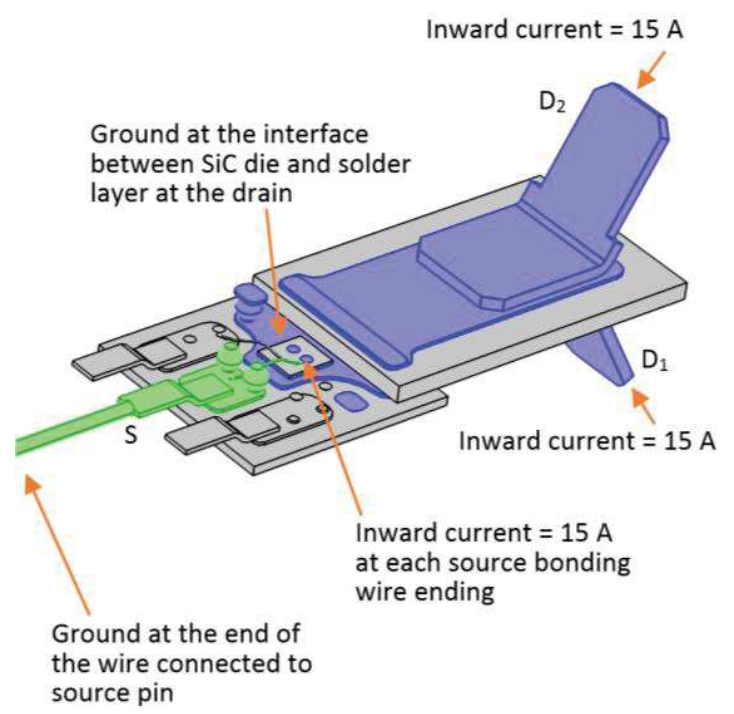

Fig. 7. Boundary conditions of Electric Currents physic: view without the top MOSFET and its ceramic substrate.

The Heat Transfer physic was set in order to couple it with the Electric Currents, which will give the current density needed to compute the heat generated by wires and copper patterns of the module. The power dissipated by the MOSFETs was set as uniform Heat Source inside the subdomains of $\mathrm{SiC}$ dice, as measured during the tests on the prototype ( $26 \mathrm{~W}$ per MOSFET). The temperature of the water at the inlet was set equal to $16{ }^{\circ} \mathrm{C}$ as measured during the thermal characterization. The Fluid Flow physic was simulated considering the subdomain of the coolant, the geometry highlighted blue in Fig. 8. The flow rate of $21 / \mathrm{min}$ lead to low Reynolds Number, then the flow was simulated as laminar.

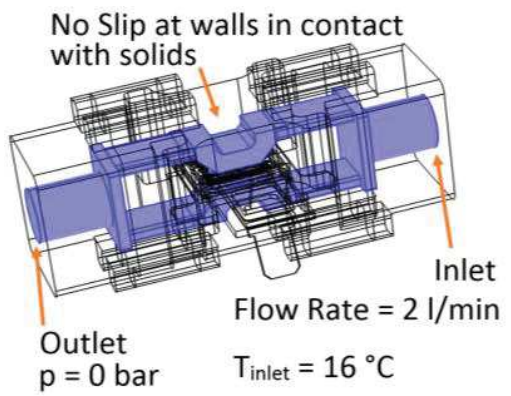

Fig. 8. 3D geometry of the coolant (water) and Laminar Flow boundary conditions.

The meshing was carried out refining the boundary layer region with the COMSOL Multiphysics built-in algorithm in order to get good simulation results of the fluid dynamics. To obtain good results by the electric simulations, a fine mesh of the copper tracks has been needed. The stationary simulations were run with about 5 millions of degrees of freedom.

Fig. 9 shows the simulation results of the accurate model taking into account the Joule heating inside the copper tracks and the wires, with dissipated power of $26 \mathrm{~W}$ per die, and a $16^{\circ} \mathrm{C}$ water flow rate of $2 \mathrm{l} / \mathrm{min}$. These values were fixed in order to compare simulations with thermal measurement performed on the module prototype (Section 3).

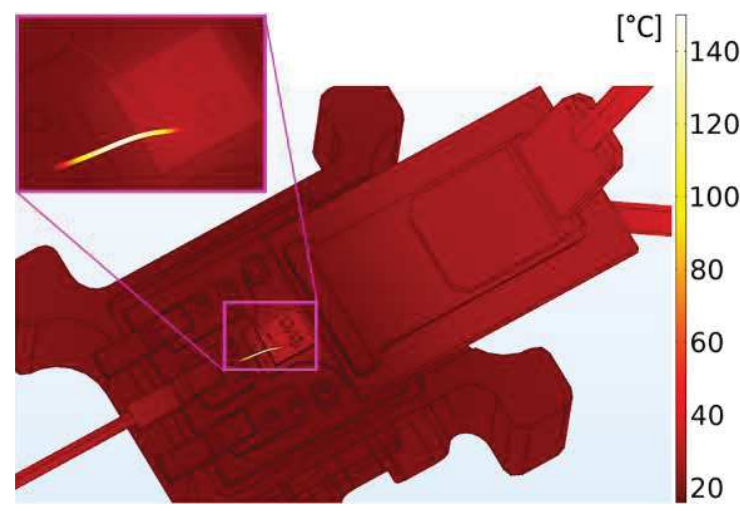

Fig. 9. Simulated thermal map (inner view) of the module dissipating $2 \times 26 \mathrm{~W}$, with a $16^{\circ} \mathrm{C}$ water flow of $21 / \mathrm{min}$.

The very high temperature of the source bondwire, visible in the inset of Fig. 9, is due to anomalous DC biasing, which implies power current flow through it, contrarily to what happens in real application. All the other parts are well below this temperature (maximum $35^{\circ} \mathrm{C}$ in the $\mathrm{SiC}$ die).

The cooling is almost symmetric with respect to the plane parallel to the copper tracks on the ceramic substrates and passing through the middle of the module. The temperature of external points, as the ones near to the drain terminals, are close to $26{ }^{\circ} \mathrm{C}$, like those measured during the thermal characterization in the same conditions. The temperature increase of the water at the outlet is around $0.3{ }^{\circ} \mathrm{C}$ as the one measured during the experimental.

Comparing these results with those of thermal characterization (Fig. 6) a $\Delta \mathrm{T}$ relative error lower than $5 \%$ was found, without any fitting parameter, then the model can be used to draw important observations related to the inner temperatures, which are not accessible by direct measurements.

Fig. 10 shows the results of early simulations with dissipated power of $100 \mathrm{~W}$ per die and $20^{\circ} \mathrm{C}$ water with flow rate of $9 \mathrm{l} / \mathrm{min}$ and without the Joule heating of copper tracks, in order to be compared with the one 
presented in [8]. In this case the maximum temperature of the MOSFETs is around $76^{\circ} \mathrm{C}$, much lower than the one obtained in [8], probably due to the more accurate modeling. Considering also the power dissipated on the copper tracks, it increases to $81{ }^{\circ} \mathrm{C}$.

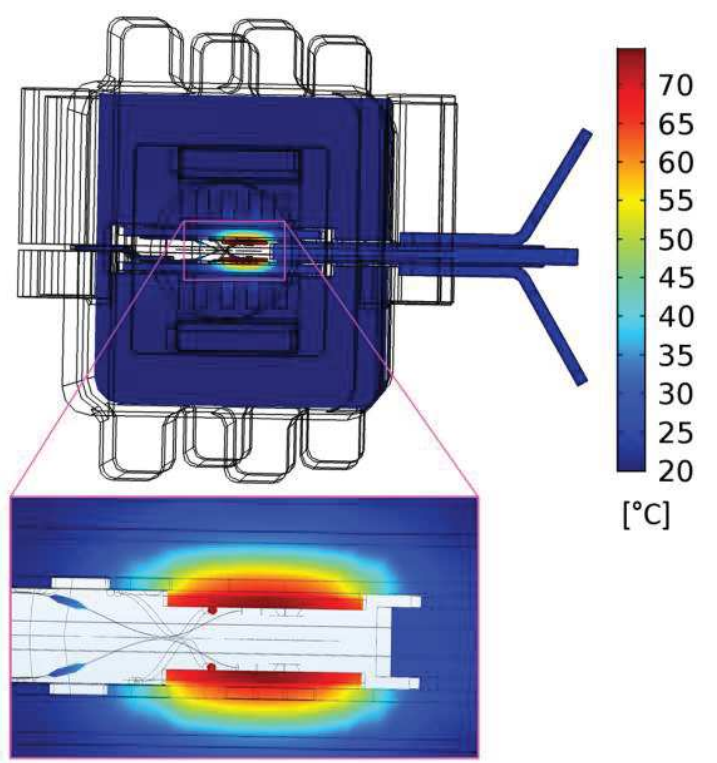

Fig. 10. Simulated thermal map (slice passing through the centre of the $\mathrm{SiC}$ subdomains) of the module dissipating $2 \times 100 \mathrm{~W}$, with a $20^{\circ} \mathrm{C}$ water flow of $91 / \mathrm{min}$.

\section{Design for reliability improvement}

By exploiting the validated numerical model, new solutions can be found to improve the thermal design. In particular three actions were explored:

- remove wirebonds and $\mathrm{Cu}$ bumps;

- enlarge source flanges;

- increase heat spreader exchange surface with the liquid coolant.

The first important issue, was to modify the electrical connection with the die. The same flat-pack technology presented in $[12,13]$ was considered in order to obtain a wireless module. Fig. 11 shows the simulated internal map with a possible wireless layout, where the source and gate contacts are made by copper flanges, which act as secondary heat spreaders, too.

The simulated maximum temperature with this solution at the same operating conditions as in Fig. 10 ( $100 \mathrm{~W}$ of dissipated power each die, flow rate $9 \mathrm{l} / \mathrm{min}$ ) is $73{ }^{\circ} \mathrm{C}$, a value similar to that shown in Fig. 10, but it must be reminded that this was obtained without accounting for the power dissipated in the tracks (otherwise it increases over $80^{\circ} \mathrm{C}$ ). This means that the heat spreading effect introduced by the new flat source contacts is effective.

With a flow rate decreased to $21 / \mathrm{min}$ (more common in real applications) the maximum MOSFETs temperature increases to $82{ }^{\circ} \mathrm{C}$.

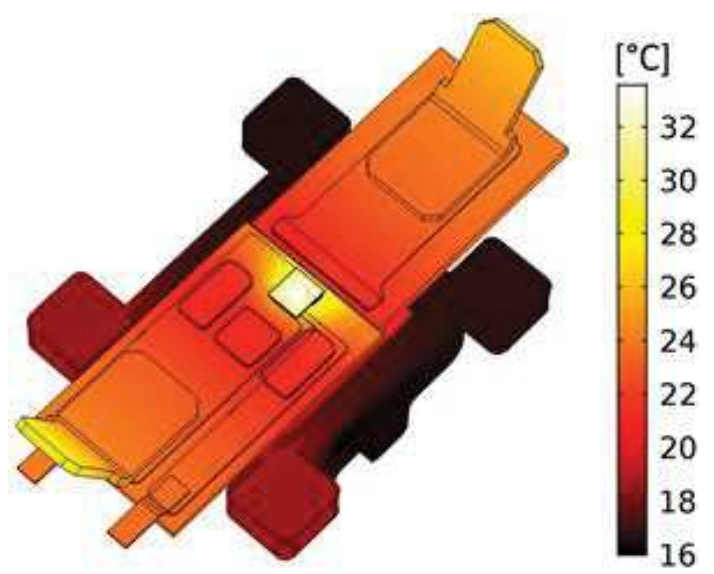

Fig. 11. Simulated thermal map of a wireless module, dissipating $2 \times 26 \mathrm{~W}$, with a $16^{\circ} \mathrm{C}$ water flow of $2 \mathrm{l} / \mathrm{min}$.

The thermal performance (then the reliability) of the module could be further improved, by increasing the exchange surface of the heat spreader: The fins shape was already optimized before to build the prototype, than a new spreader, with pins instead of fins, was studied. Since this modification influences not only the exchange surface, but also the fluid dynamics, simulations with different numbers and height of the pins were performed, to optimize the design of the heat spreader.

Fig. 12 shows the heat spreader geometry for the two proposed solutions: a) finned; b) pinned. As expected, the simulation of the latter gives better results (Fig. 13), due both to the larger heat transfer surface area, and to the increase of vorticity in the fluid dynamics. In the case of pinned heat spreader the MOSFETs maximum temperature is limited to $75^{\circ} \mathrm{C}$, even with a flow rate of $2 \mathrm{l} / \mathrm{min}$. This performance is at the state of the art, if compared with SiC 3D integrated systems literature [14].

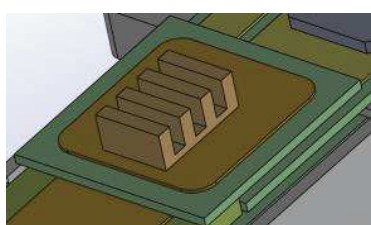

a)

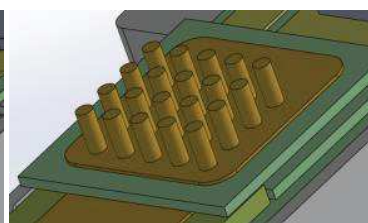

b)
Fig. 12. Detail of the heat spreader geometry for the two simulated solutions: a) finned; b) pinned. 


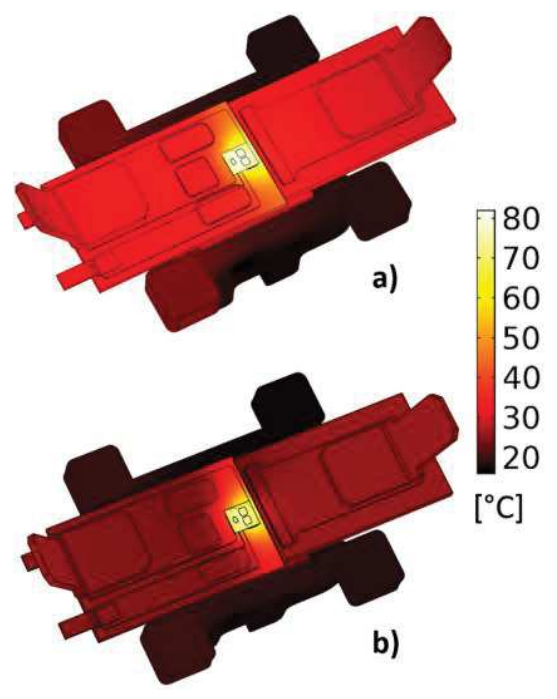

Fig. 13. Internal temperature map simulated with finned (a) and pinned (b) heat spreader. Flow rate is $21 / \mathrm{min}$, $\mathrm{T}_{\text {inlet }}=16^{\circ} \mathrm{C}, \mathrm{P}_{\text {diss }}=2 \times 100 \mathrm{~W}$. MOSFETs temperature: a) $\mathrm{T}_{\max }=82^{\circ} \mathrm{C}$; b) $\mathrm{T}_{\max }=75^{\circ} \mathrm{C}$

\section{Conclusions}

A new thermal design of modular direct liquid cooled packaging for $1200 \mathrm{~V}-35 \mathrm{~A}$ SiC power MOSFET module was developed. A 3D thermal fluid dynamic model was setup and tuned by accurate thermal characterization of a first prototype. The numerical model was then used to explore different solutions for thermal performance improving, in order to limit both thermal and thermo-mechanical degradation mechanisms.

The new design is based on a wireless flat-pack technology already developed for a different application. By thermal fluid dynamic simulations, many solutions were studied to improve the heat removal capacity, and the results for two of them were presented. The module is able to dissipate $2 \times 100 \mathrm{~W}$ (with an inlet water temperature of $16^{\circ} \mathrm{C}$ and a flow rate of $21 / \mathrm{min}$ ), keeping the transistors temperature lower than $80^{\circ} \mathrm{C}$, which represent a valuable result, compared to the state of the art. At the same time, the module, being now totally bondless, could be more effective also for applications in harsh environment.

\section{References}

[1] B.C. Charboneau, F. Wang, J.D. Van Wyk, D. Boroyevich, Z. Liang, E.P. Scott, C.W. Tipton, "Double-sided liquid cooling for power semiconductor devices using embedded power packaging", IEEE Trans. Ind. Appl., vol. 44, no. 5, pp. 1645-1655, 2008.
[2] "DENSO Develops high output power control unit and battery cooling system for hybrid vehicles". DENSO news ref. N. D0705 05/31/2007, 2007.

[3] X. Cao, T. Wang, Z. Tan, K. Ngo, S. Luo, G.-Q. Lu, "Development of a double-side cooled power module joined by low-temperature sintering of nanosilver paste for electric vehicles", in IMAPS's $2^{\text {nd }}$ Advanced Technology Workshop on Automotive Microelec. and Packaging, 2010.

[4] J. Marcinkowski, "Innovative CooliR2 TM packaging platform with dual-side cooling advances HEVs and EVs", IR technical paper, www.irf.com/technicalinfo/whitepaper/coolir2d.pdf.

[5] M. Schneider-Ramelow, "Design and assembly of power semiconductors with double-sided water cooling," proc. $5^{\text {th }}$ International Conference on Integrated Power Systems (CIPS), 2008, pp. 1-7.

[6] M. Meisser, D. Hamilton, T. Blank, and P. Mawby, "Low-inductive compact $\mathrm{SiC}$ power modules for highfrequency operation", proc. PCIM Europe 2014.

[7] M. Schmenger, M. Meisser, D. Hamilton, B. Leyrer, M. Bernd, P. Mawby, and T. Blank, "Highly integrated power modules based on copper thick-film-on-DCB for high frequency operation of $\mathrm{SiC}$ semiconductors design and manufacture", proc. $17^{\text {th }}$ EPE Conf., 2015.

[8] P. Lasserre, D. Lambert, A. Castellazzi, IEEE $4^{\text {th }}$ Workshop on Wide Bandgap Power Devices and Applications (WiPDA), pp. 188-193, 7-9 Nov. 2016.

[9] M. Pecht, "The Influence of Temperature on Microelectronic Device Failure Mechanisms", , RAMSEARCH Co, CROFTON MD (USA), Final rep. US Army SBIR Phase II, 1993.

[10] J. C. Irvin, "The Reliability of GaAs FETs," Ch. 6 in GaAs FET Principles and Technology, J. Di Lorenzo and D. Khandelwal, Editors, Artech House, Mass., pp. 348-400, 1985.

[11] COMSOL Multiphysics, "AC/DC Module user's guide", 2015.

[12] A.K. Solomon, A. Castellazzi, N. Delmonte, P. Cova, "Highly integrated low-inductive power switches using double-etched substrates with through-hole viases", proc. ISPSD, pp. 329-332, 2015

[13] P. Cova, N. Delmonte, A.K. Solomon, A. Castellazzi, "Thermal design optimization of novel modular power converter assembly enabling higher performance, reliability and availability", Microel. Reliab., vol. 64, pp. 507-512, 2016.

[14] S. Seal, H.A. Mantooth, "High performance silicon carbide power packaging - past trends, present practices, and future directions", Energies, vol. 10, no 3, pp. 1-30, 2017. 